\title{
Reference Design of the Mu2e Detector Solenoid
}

\author{
S. Feher, N. Andreev. J. Brandt, S. Cheban, R. Coleman, N. Dhanaraj, I. Fang, M. Lamm, V. Lombardo, M. Lopes, \\ J. Miller, R. Ostojic, D. Orris, T. Page, T. Peterson, Z. Tang, R. Wands
}

\begin{abstract}
The Mu2e experiment at Fermilab has been approved by the Department of Energy to proceed developing the preliminary design. Integral to the success of Mu2e is the superconducting solenoid system. One of the three major solenoids is the Detector Solenoid that houses the stopping target and the detectors. The goal of the Detector Solenoid team is to produce detailed design specifications that are sufficient for vendors to produce the final design drawings, tooling and fabrication procedures and proceed to production. In this paper we summarize the Reference Design of the Detector Solenoid.
\end{abstract}

Index Terms-Detector, magnet, solenoid, superconducting.

\section{INTRODUCTION}

$\mathrm{T}$ HE Muon-to-Electron conversion experiment (Mu2e), under development at Fermilab [1], will search for evidence of new particles (beyond the very successful Standard Model) by detecting electrons originating from neutrino-less conversion of the muon under the nuclear force. This simple goal, however, can only be achieved with a complicated experimental setup that includes an $8 \mathrm{~kW} 8 \mathrm{GeV}$ proton beam interacting with a tungsten target to generate muons, and a complex solenoid magnetic field that filters and guides the muons into the detector region where the conversion electrons are identified and their momentum is measured.

The Mu2e magnet system (see Fig. 1) [2] consists of three large superconducting solenoids: Production Solenoid, Transport Solenoid and Detector Solenoid. The last in the chain of magnets, the Detector Solenoid (DS) [3], houses the muon stopping target and the detectors. The role of the DS is to i) maximize muon yield by efficiently focusing muons to the stopping target, ii) efficiently focus conversion electrons from the stopping target towards the detectors and iii) provide a solenoid field as part of the tracker spectrometer. These goals can be achieved by a solenoid field that has $4.2 \mathrm{~m}$ long graded $(2 \mathrm{~T}-1 \mathrm{~T})$ and a $5.2 \mathrm{~m}$ long uniform (1T) sections.

In this paper we summarize the Reference Design (RD that contains all design specifications of the Detector Solenoid.

Manuscript received July 16, 2013. This work was supported in part by the Fermi Research Alliance under DOE Contract DE-AC02-07CH1 1359.

S. Feher is with Fermilab, Batavia, IL 60510. Phone: +1-630-840-2240, fax : +1-630-840-2323, e-mail: fehers@fnal.gov.

R. Ostojic is with CERN, Geneva, Switzerland.

N. Andreev, J. Brandt, S. Cheban, R. Coleman, N. Dhanaraj, I. Fang, M. Lamm, V. Lombardo, M. Lopes, D. Orris, T. Page, R. T. Peterson, Z. Tang and R. Wands are with Fermilab, Batavia, IL 60510, USA.

J. Miller is with Boston University, Boston, MA 02215, USA.

\section{Detector Solenoid OVERVIEW}

The $10.75 \mathrm{~m}$ long and $1.9 \mathrm{~m}$ inner bore diameter Mu2e Detector Solenoid utilizes two and one layer coils that are wound from two different types of aluminum stabilized $\mathrm{NbTi}$ superconductor cable. At the magnet operational current of $6114 \mathrm{~A}$ (at $5 \mathrm{~K}$ coil temperature) the coil peak field on the conductor in the graded section $(2 \mathrm{~T}-1 \mathrm{~T}$ linearly decreasing field in the bore) is $2.2 \mathrm{~T}$ while in the spectrometer section ( $1 \mathrm{~T}$ in the bore) is $1.3 \mathrm{~T}$. The DS cold mass and cryostat weighs about $9 \mathrm{t}$ and $30 \mathrm{t}$ respectively. The stored energy is 30 MJ.

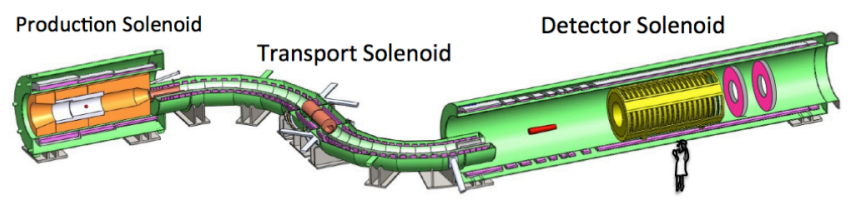

Fig. 1. Layout of the Mu2e Solenoid system.

\section{MAGNETIC DESIGN}

The magnetic design specifies the solenoid field map for the Mu2e experiment, the coil layout (coil dimensions and spacing) and the operational current. The coil structure of the Mu2e solenoid system is shown in Fig. 2. DS overlaps the three last coils of the Transport Solenoid consequently the field map takes into account the field originated from the Transport Solenoid as well.

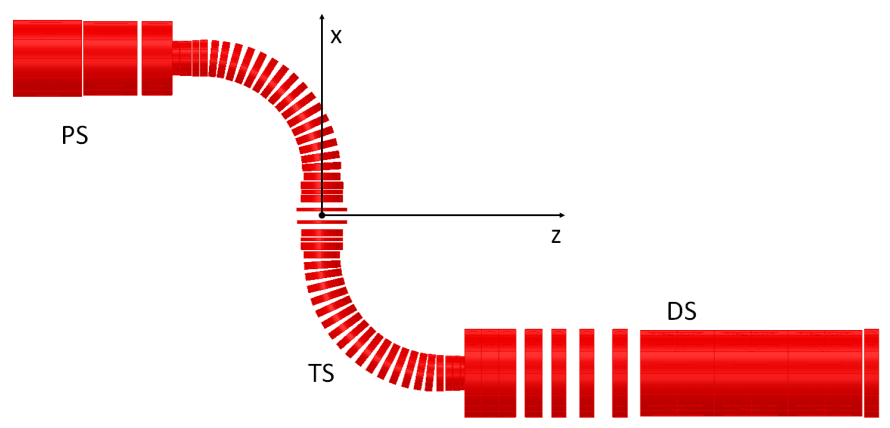

Fig. 2. Mu2e Solenoid System Coil layout; Production Solenoid (PS), Transport Solenoid (TS) and Detector Solenoid (DS).

The magnetic field at two radial positions (in the center of the solenoid and $\mathrm{R}=0.4 \mathrm{~m}$ ) is shown in Fig. 3. In the graded section (S1) at the entrance to the DS the field is $2 \mathrm{~T}$ then it gradually drops to $1 \mathrm{~T}$ at the beginning of the spectrometer 
section (S3). In the spectrometer section the field is $1 \mathrm{~T}$ and it has a slight negative gradient. In Fig. 4 the field tolerance values obtained by extensive studies that are based on coil manufacturing tolerances are shown. The detailed studies of the tolerances and their importance to the Mu2e experiment are presented in [4].

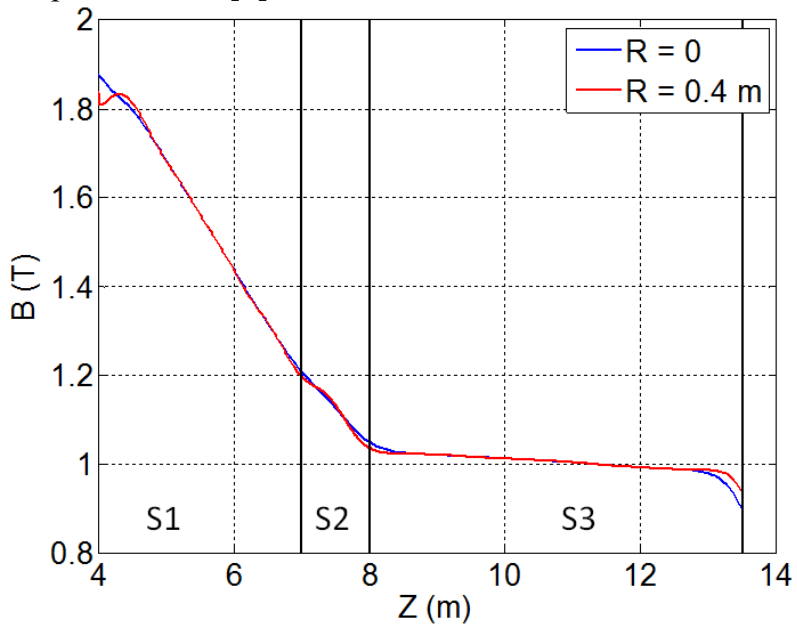

Fig. 3. - Magnetic field at different radii. S1 is the gradient region, $\mathrm{S} 2$ is transition region, $\mathrm{S} 3$ is the spectrometer region.

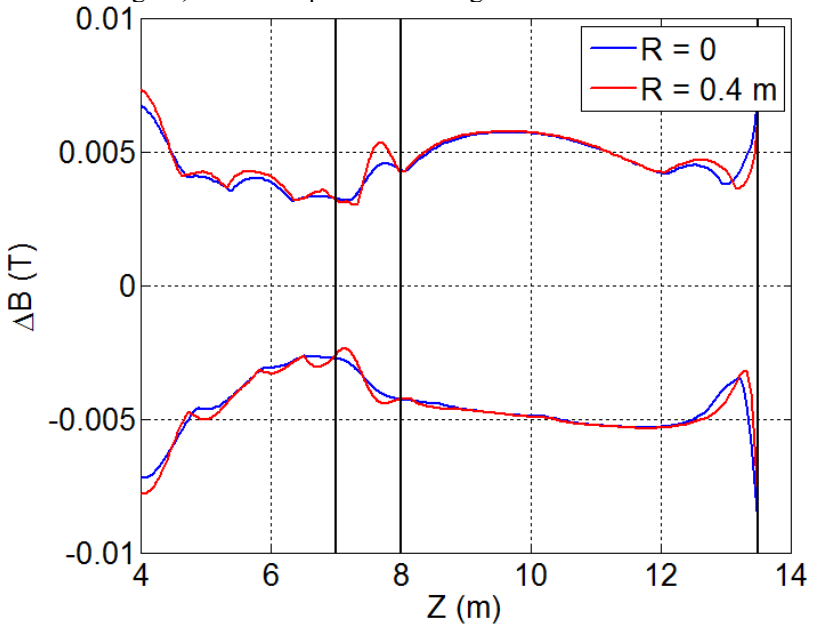

Fig. 4. - Magnetic field difference between the nominal field and the field when conductors have a 50 micron variation in thickness.

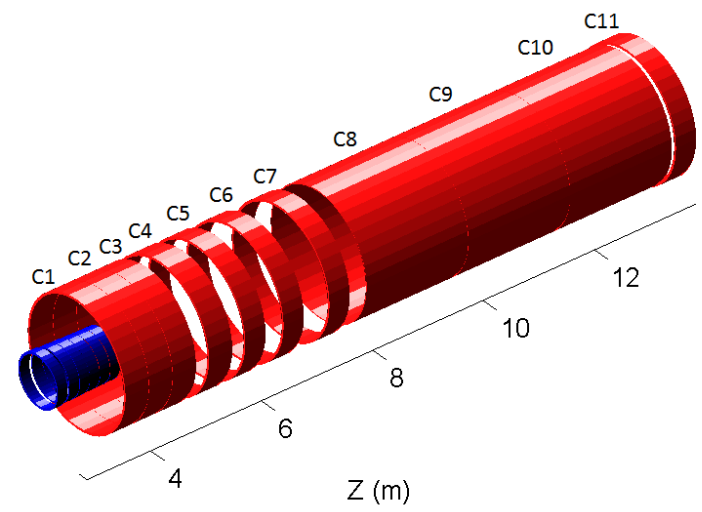

Fig. 5. Detail of the DS coils and the three TS coils overlapped by DS.

The coil dimensions and spacing in the Mu2e coordinate system are presented in Table I. The coils labeling is presented in Fig. 5. The field specifications tolerances could accommodate the following manufacturing tolerances: i) \pm 50 $\mu \mathrm{m}$ cable thickness, ii) $\pm 5 \mathrm{~mm}$ radial and $\pm 1 \mathrm{~mm}$ longitudinal positioning of the coils with respect to each other, iii) coils must be aligned within 2 mrad with respect to the magnet axes. These tolerance values assume that the coil positions are adjusted by choosing the correct spacer length after the coil lengths are precisely measured.

TABLE I

Summary OF DETECTOR SOLENOID COIL PARAMETERS

\begin{tabular}{ccccccc}
\hline $\begin{array}{c}\text { Coil } \\
\#\end{array}$ & $\begin{array}{c}\text { Coil IR } \\
{[\mathrm{m}]}\end{array}$ & $\begin{array}{c}\text { Coil } \\
\text { OR }[\mathrm{m}]\end{array}$ & $\begin{array}{c}\text { Coil } \\
\text { Length } \\
{[\mathrm{m}]}\end{array}$ & $\begin{array}{c}\text { Z at the } \\
\text { Center } \\
{[\mathrm{m}]}\end{array}$ & layers & $\begin{array}{c}\text { Total } \\
\text { turns }\end{array}$ \\
\hline 1 & 1.0500 & 1.0915 & 0.4198 & 3.7489 & 2 & 146 \\
2 & 1.0500 & 1.0915 & 0.4198 & 4.1739 & 2 & 146 \\
3 & 1.0500 & 1.0915 & 0.4198 & 4.5989 & 2 & 146 \\
4 & 1.0500 & 1.0915 & 0.4198 & 5.2519 & 2 & 146 \\
5 & 1.0500 & 1.0915 & 0.3623 & 5.8801 & 2 & 126 \\
6 & 1.0500 & 1.0915 & 0.3623 & 6.5701 & 2 & 126 \\
7 & 1.0500 & 1.0915 & 0.3623 & 7.3971 & 2 & 126 \\
8 & 1.0500 & 1.0705 & 1.8300 & 8.8178 & 1 & 244 \\
9 & 1.0500 & 1.0705 & 1.8300 & 10.6528 & 1 & 244 \\
10 & 1.0500 & 1.0705 & 1.8300 & 12.4883 & 1 & 244 \\
11 & 1.0500 & 1.0915 & 0.3623 & 13.6425 & 2 & 126 \\
\hline \hline
\end{tabular}

\section{CABLE Design}

The DS utilizes two different types of aluminum stabilized Rutherford cables (DS1 - used for the double layer coils and DS2 - used for the single layer coils). Based on detailed specifications ${ }^{1}$ the prototype versions of these two types of cables have been ordered from two different vendors. Table II and Table III summarizes the main parameters of the strand and cables respectively.

To avoid unnecessary risk procuring the strand and cable we have chosen specifications that are similar to specs of Detector Solenoids that have already been successfully used by other experiments. The specifications for the conductor includes a rigorous Quality Assurance program require qualifications tests and material certifications during all phases of the fabrications process. The fine details of the specs also reflect the input from vendors during the procurement process of the prototype cables.

\section{CoIL Design}

As shown in Fig. 5 the DS is made of 11 coils. Seven two layer coils are in the gradient section (S1); three (long) one layer and one (short) two layer coils at the downstream end of the spectrometer section (S3). From the manufacturing point of view there are only three different types of coils.

The DS employs a composite cable insulation made of polyimide and pre-preg glass tapes. This type of insulation, originally developed for the TRISTAN/TOPAZ solenoid [5], was also used in the ATLAS Central Solenoid [6]. The cable is insulated with two layers of composite tape consisting of 25

\footnotetext{
${ }^{1}$ The specifications documents are available upon request.
} 
$\mu \mathrm{m}$ Kapton tape sandwiched between $25 \mu \mathrm{m}$ of a semi-dry (BT) epoxy on one side and $75 \mu \mathrm{m}$ of pre-preg E-glass on the other side. The total thickness of this composite tape is 125 $\mu \mathrm{m}$. The cable is butt-wrapped with 2 layers of the composite tape. Therefore the cable insulation thickness is $250 \mu \mathrm{m}$.

TABLE II

SUMmaRY OF DETECTOR SOlENOID STRAND PARAMETERS

\begin{tabular}{lccc}
\hline \hline Parameters & Unit & Value & Tolerance \\
\hline Outer Diameter & $\mathrm{mm}$ & 1.303 & \pm 0.005 \\
Cu/Sc ratio & & $1: 1$ & \pm 0.1 \\
Filament OD & $\mu \mathrm{m}$ & 40 & - \\
Ic $(4.22 \mathrm{~K}, 5 \mathrm{~T})$ & $\mathrm{A}$ & 1850 & \\
Min RRR & & 80 & - \\
Twist direction & & Left & \\
Twist pitch & $\mathrm{mm}$ & 30 & \pm 4 \\
\hline \hline
\end{tabular}

TABLE III

Summary of Detector Solenoid Cable Parameters

\begin{tabular}{llllll}
\hline \hline Rutherfod & Parameters & Unit & DS1 & DS2 & Toler. \\
\cline { 2 - 6 } Cable & No strands & & 12 & 8 & - \\
& width & $\mathrm{mm}$ & 7.88 & 5.25 & \pm 0.01 \\
& thickness at 5 kPsi & $\mathrm{mm}$ & 2.34 & 2.34 & \pm 0.01 \\
& Transp. angle & degree & 15 & 15 & \pm 0.5 \\
& Lay direction & & Right & Right & - \\
& Minimum Ic & $\mathrm{kA}$ & 20.9 & 13.9 & - \\
& (at 4.22 K, 5T) & & & & \\
& Min RRR & & $\geq 60$ & $\geq 60$ & \\
& Cable residual twist & degree & $<45$ & $<45$ & \\
& Min bending radius & $\mathrm{mm}$ & 20 & 20 & \\
Aluminum \\
cladded & Minimum Ic & $\mathrm{kA}$ & $>18.8$ & $>12.5$ & \\
cable & (at 4.22 K, 5T) & & & & \\
& width & $\mathrm{mm}$ & 20.1 & 20.1 & \pm 0.1 \\
& thickness & $\mathrm{mm}$ & 5.27 & 7.03 & \pm 0.03 \\
& Strand Copper RRR & & $>80$ & $>80$ & \\
& Aluminum RRR & & $>800$ & $>800$ & \\
& Yield stress at 293 K & $\mathrm{MPa}$ & $>30$ & $>30$ & \\
& Yield stress at 4.22 K & $\mathrm{MPa}$ & $>40$ & $>40$ & \\
& Shear stress Al-strand & $\mathrm{MPa}$ & $>20$ & $>20$ & \\
\hline \hline
\end{tabular}

The coils are wound onto a collapsible mandrel. The recommended tension and the compaction criteria during the winding process are similar to what was for the CDF central solenoid [7]. The layers for the two layer coils are wound continuously and sheets of dry E-glass insulation $(0.5 \mathrm{~mm}$ thick) are introduced between the coil layers. There is also extra ( $2 \mathrm{~mm}$ thick) ground insulation between the coil and the support structure that consists of dry E-glass and $2 \times 25 \mu \mathrm{m}$ layers of Kapton. The extra thickness of E-glass between the coil and support structure allows for the machining of the outer coil surface after the impregnation to obtain the $0.05 \mathrm{~mm}$ tolerance value for the outer radius of the coil that is required for controlled shrink-fitting the surfaces of the support shells and the coils. The support shells are made of 5083-0 aluminum and they are $1 \mathrm{~cm}$ (for single layer coil) and $2 \mathrm{~cm}$ (for double layer coil) thick. Before the slightly oversized shell is milled to precise ID $(0.05 \mathrm{~mm}$ tolerance) all the necessary welding activities need to be completed.

The coils will be cured and vacuum-impregnated. These two processes can be performed simultaneously or in series. The mandrel will remain in the coil during these manufacturing processes. The mandrel will be removed after the shrink fit is completed. The maximum interference value between the coil and the support cylinder needs to be within $0.5 \mathrm{~mm}$ with $0.05 \mathrm{~mm}$ tolerance values in order to allow adequate preload on the coil. Before the coil is inserted the cylinder will be heated up to $130 \mathrm{C}$ and a thin layer of epoxy will be put on the cylinder inner surface.

\section{COLD MASS DESIGN}

After each coil module is built, their length will be measured precisely. Based on the coil dimensions the axial spacers' length will be determined and the spacers will be fabricated within $1 \mathrm{~mm}$ axial tolerance values. Radial tolerance values of the spacers are not critical; however, the bolt hole patterns of the flanges need to be matched with that of the coil support cylinders. To avoid losing pre-compression the coils are bolted together with high strength Aluminum bolts. The detailed calculation of sizing the screws are based on DS loads and screw properties.

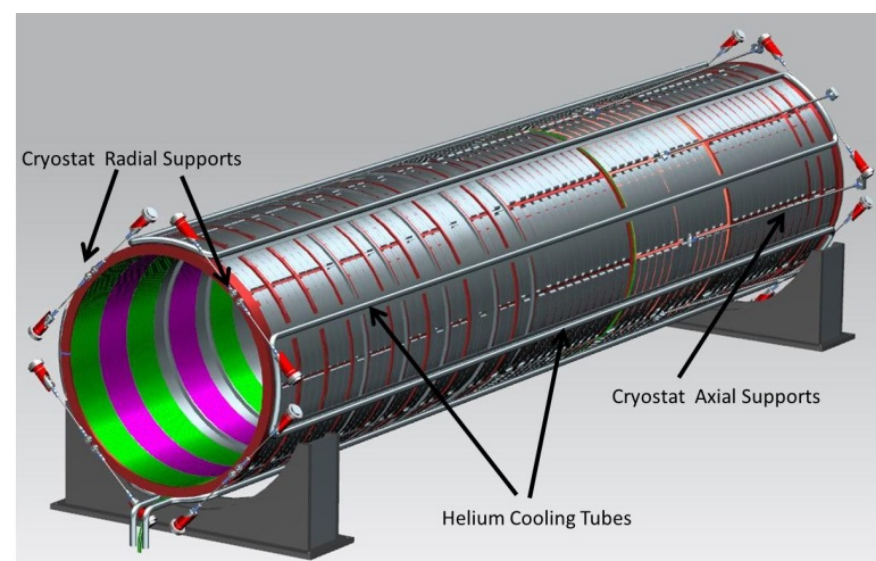

Fig. 6. DS coil and axial spacer assembly with cooling tubes and cryostat supports.

The coils are electrically connected in series. The cable joints are welded together on the wide sides of the cable. Exact length still needs to be specified. The internal bus utilizes DS1 type of conductor. The Helium cooling tubes are made from 2 inch OD Aluminum tubing. The cooling tube arrangement (Fig. 6) was optimized for the force flow-cooling scheme. The cooling tubes are attached to the support cylinder through flexible high heat conductivity aluminum strips.

\section{CRYOSTAT DESIGN}

The DS cryostat (Fig. 7) is $10.75 \mathrm{~m}$ long. The cryostat vessel is made of two concentric SS cylinders that have $2 \mathrm{~cm}$ wall thicknesses. The design satisfies ASME code Section VIII, Div. 1 rules for cylindrical shells under external pressure of 1 atmosphere at room temperature. The inner shell will be supporting the detectors sitting on a rail system. Due to the load of 10 metric tons (detectors, shielding and other equipment) the maximum vertical deformation of the inner shell is $1.0 \mathrm{~mm}$.

The DS cold mass support system (see Fig. 6) uses 16 tangentially-arranged metallic rods, eight on each ends, to 
support against dead weight and radial de-centering forces. Eight metallic rods at the downstream end only provide support against the axial magnetic forces.

The radial and the axial support rods are made from Inconel 718, and all supports are connected to their 5083-0 Al bracket at the cold mass by one inch diameter Inconel 718 pins. Both support systems use spherical rod ends to account for motion during cool-down, including the axial thermal contraction of $36 \mathrm{~mm}$ at the upstream end.

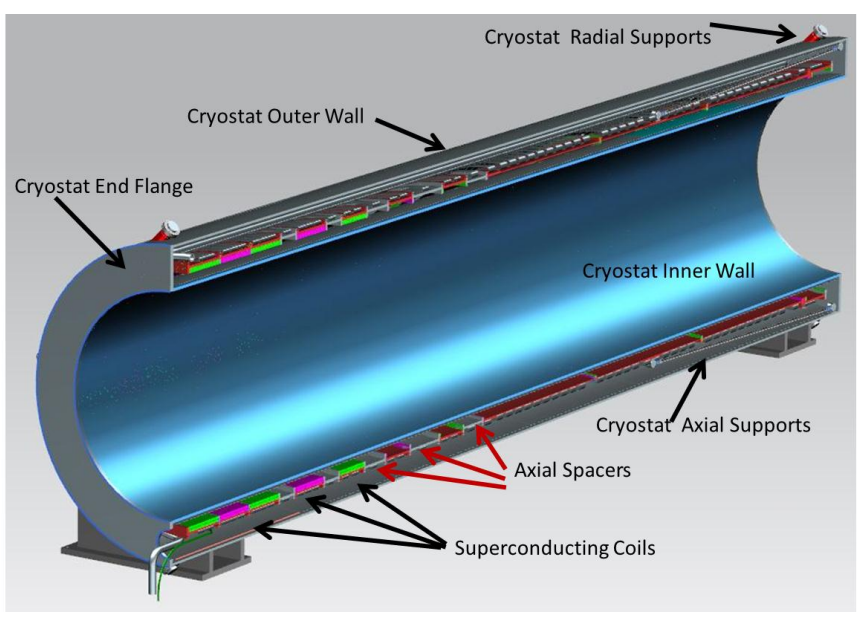

Fig. 7. Cross section of DS magnet-in cryostat. Coils are colored to distinguish them from axial spacers.

The cryostat sits on two saddles, positioned very close to the ends of the vessel, right there where the warm end of the axial supports are attached to the cryostat through towers (Fig. 7). This way the cryostat outer shell is directly transmitting the forces (100 tons axial) to the saddle support producing no stresses on the cryostat.

\section{INSTRUMENTATION}

The DS instrumentation serves for: 1) quench protection and monitoring (QPM); 2) cryogenic monitoring and controls (CMC); and 3) mechanical characterization (MC). The primary (P) sensors for quench detection are voltage taps. Holes will be drilled and tapped in the aluminium conductor so voltage taps can be attached using screws. Two voltage taps will be installed across each splice for redundancy (R). Temperature sensors will also be installed on each support cylinder for a secondary quench trigger.

Instrumentation will also be implemented for cryogenic monitoring and controls for cool down, warm up, operational steady state, and changes in response to a heat load. Temperature sensors will be installed for monitoring the temperatures of the $80 \mathrm{~K}$ shield, the cold mass, and the support posts. In addition, temperature sensors and heaters will be installed along the bore for monitoring and controlling its temperature.

The mechanical state of the solenoid will be monitored using strain gauges and position sensors. Several strain gauges will be installed on the upstream, downstream, and longitudinal supports. Table IV summarizes the different type and number of sensors envisioned to be used in the DS.
TABLE IV

DS Instrumentation List

\begin{tabular}{|c|c|c|}
\hline Sensor Type & Description & Function \\
\hline Coil Voltage Taps & $12 \mathrm{P} / 12 \mathrm{R}$ & Primary QPM \\
\hline Cold Mass RTDs & 11P/11R Cernox ${ }^{\mathrm{TM}}$ & Secondary QPM \\
\hline Lead Voltage Taps & $4 \mathrm{P} / 4 \mathrm{R}$ & Primary SC Lead QPM \\
\hline Lead LTS Wire & $\begin{array}{l}\text { NbTi SC Wires, } \\
\text { 2P/2R }\end{array}$ & Secondary SC Lead QPM \\
\hline 80K Shield RTDs & 10 Platinum & $\mathrm{CMC}$ \\
\hline Cold Mass RTDs & 10 Cernox $^{\mathrm{TM}}$ & $\mathrm{CMC}$ \\
\hline Bore RTDs & 12 Platinum & CMC (Bore Temp. Control) \\
\hline Bore Heaters & $1 \mathrm{P} / 1 \mathrm{R}$ & CMC (Bore Temp. Control) \\
\hline Phase Separator & He LL Probe, & CMC (Helium Flow \\
\hline Liquid Level & $1 \mathrm{P} / 1 \mathrm{R}$ & Control) \\
\hline Phase Separator & 5 Cernox $^{\mathrm{TM}}$ & CMC (Helium Flow \\
\hline RTD Liquid Level & & Control) \\
\hline $\begin{array}{l}\text { Support Post } \\
\text { RTDs }\end{array}$ & 20 Cernox $^{\mathrm{TM}}$ & $\mathrm{CMC}$ \\
\hline $\begin{array}{l}\text { Support Post } \\
\text { RTDs }\end{array}$ & 20 Platinum & $\mathrm{CMC}$ \\
\hline $\begin{array}{l}\text { Support Post } \\
\text { Strain Gauges }\end{array}$ & 32 Half-Bridge & MC (Coil Support Stress) \\
\hline $\begin{array}{l}\text { Cold Mass } \\
\text { Position Sensors }\end{array}$ & $6 \mathrm{P} / 6 \mathrm{R}$ & MC (Coil Displacement) \\
\hline
\end{tabular}

\section{INTERFACES}

The DS has many interfaces with other parts of the Mu2e Experiment: cryostat inner shell, flanges between DS and TS and flanges between DS and vacuum pump spool piece, port for the transfer line and the magnet support. The design of these interfaces are in the final design phase.

\section{COnClusions}

The Mu2e experiment requires $2 \mathrm{~T}-1 \mathrm{~T}$ strong, $10.75 \mathrm{~m}$ long, large $(1.9 \mathrm{~m})$ OD bore magnets to house the stopping target and the detectors. Most of the design considerations have been completed and the reference design is close to completion. A summary of the specifications was presented for the field, conductor, coil, cold mass, cryostat and instrumentation design.

\section{REFERENCES}

[1] Mu2e Collaboration, "Mu2e Conceptual Design Report", arXiv:1211.7019, http://arxiv.org/abs/1211.7019.

[2] M.J. Lamm et al., "Solenoid Magnet System for the Fermilab Mu2e Experiment",IEEE Transaction on Applied Superconductivity, vol. 22, Issue 3, pp. 4100604, June 2013.

[3] R. Ostojic et al., "Challenges in the Design of the Detector Solenoid for the Mu2e Experiment",IEEE Transaction on Applied Superconductivity, vol. 23, Issue 3, pp. 4500404, June 2013.

[4] M. Lopes et al. "Tolerance studies of the Mu2e solenoid system" - IEEE Trans. Appl. Supercond. 23 submitted for publication.

[5] A. Yamamoto et al. " A Thin Superconducting Solenoid Wound With Internal Winding Method for Colliding Beam Experiments “,J. Phys. Colloques, vol. 45, pp. C1-337-C1-340, 1984.

[6] Atlas Central Solenoid, ATLAS TDR-9; CERN/LHCC 97-21, April 1997.

[7] H. Minemura et al., "Construction and testing of a 3 m diameter x $5 \mathrm{~m}$ superconducting solenoid for the Fermilab collider detector facility (CDF) ”, Nucl. Instrum. Methods A, vol. 238, pp. 18-34, July 1985. 